\title{
Histiocitoma fibroso maligno de cordón espermático. Presentación de un caso y revisión de la literatura
}

\author{
Martín Martín S, Müller Arteaga C, García Lagarto E, Sanz Ruiz A, Rivero Martínez MD, \\ Fernández del Busto E.
}

Servicio de Urología. Hospital Clínico Universitario de Valladolid.

Actas Urol Esp. 2008;32(7):745-748

\section{RESUMEN}

HISTIOCITOMA FIBROSO MALIGNO DE CORDON ESPERMÁTICO. PRESENTACIÓN DE UN CASO Y REVISIÓN DE LA LITERATURA

Presentamos un caso de un histiocitoma fibroso maligno (HFM) de cordón espermático.

Un varón de 80 años fue admitido en nuestro hospital con una masa escrotal izquierda, relacionada con un traumatismo genital hacia varios meses. Ante la sospecha de un tumor testicular, se practicó una orquiectomia radical izquierda. El examen histológico de la masa tumoral, reveló un Histiocitoma fibroso maligno. El tumor estaba firmemente adherido al cordón espermático. El HFM es un tumor de alta malignidad derivado del tejido conectivo, el cual puede ocasionalmente, afectar al tracto genital masculino. No hay acuerdo respecto a un tratamiento principal y el pronóstico en general, es pobre.

Palabras clave: Histiocitoma fibroso maligno. Cordón espermático. Tumor paratesticular.

\section{ABSTRACT}

MALIGNANT FIBROUS HISTIOCYTOMA OF THE SPERMATIC CORD. PRESENTATION OF ONE CASE AND LITERATURE REVISION

We present a case of malignant fibrous histiocytoma (MFH) of the spermatic cord. An 80-years old man was admitted to the hospital with a left scrotal mass, related to a genital traumatism several months ago. Under the suspicion of a testicular tumor, left radical orchiectomy was performed. Histological examination of the tumoral mass revealed a malignant fibrous histiocytoma. The tumor was firmly adhered to the spermatic cord. MFH is an extremely rare, highly malignant connective tissue tumor, which may, occasionally, affect the male genital tract. There are no agreed treatment principles. The overall prognosis is poor.

Keywords: Malignant fibrous histiocytoma. Spermatic cord. Paratesticular tumors.

$\mathrm{L}^{\mathrm{os}}$ os tumores paratesticulares son infrecuentes y presentan una alta tasa de malignidad. Se ha estimado que el 70\% de estas lesiones son benignas y el $30 \%$ malignas. Para comprender mejor esta patología tumoral, vamos a comentar lo que se entiende por región paratesticular. Esta zona está constituida por el sistema colector testicular, que incluye la rete testis, el epidídimo y los conductos deferentes. Existen una serie de estructuras derivadas del mesonefros primitivo y del paramesonefros. La túnica vaginal también se incluye en esta región y puede ser origen de procesos quísticos o neoplásicos.
El componente más importante es el cordón espermático, del que se originan el $90 \%$ de las neoplasias ${ }^{1}$.

El histiocitoma fibroso maligno es el tumor de tejidos blandos más frecuente en extremidades y retroperitoneo ${ }^{2}$. Su aparición en el cordón espermático es excepcional, y según nuestra bibliografía son pocos los casos publicados, siendo éste el tercer caso presentado en la literatura española ${ }^{3,4}$.

\section{CASO CLÍNICO}

Se trata de un varón de 80 años de edad que presenta como antecedentes de interés una adenomec- 
tomía tipo Freyer por HBP, cardiopatía isquémica y un angiomiolipoma de $1 \mathrm{~cm}$. en riñón derecho controlado por ecografía.

Dicho paciente acude a nuestro Hospital por presentar una masa indolora en hemiescroto izquierdo de meses de evolución, relacionada con un traumatismo genital.

En la exploración física se objetiva un testículo izquierdo aumentado de tamaño, el cual parece estar englobado en una masa pétrea, no dolorosa, sin signos de inflamación, con transiluminación negativa. No se palpan adenopatías regionales. En la ecografía (Fig. 1) se evidencia una masa extratesticular heterogénea de $70 \times 27 \mathrm{~mm}$ en la zona superior del saco escrotal con marcado contenido líquido peritesticular, en probable relación con hematocele evolucionado. Se realizan marcadores tumorales Alfa FP, Beta HCG y LDH con valores normales.

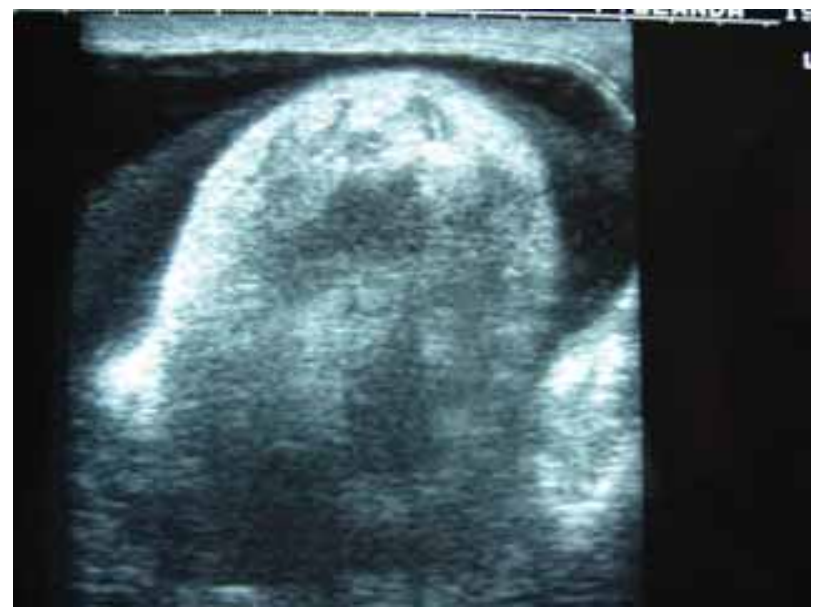

FIGURA 1. En la ecografia se observa una masa extratesticular heterogénea de $70 \times 27 \mathrm{~mm}$ en la zona superior del saco escrotal con marcado contenido líquido peritesticular.

Se propone al enfermo la orquiectomía, pero prefiere control ambulatorio con nueva ecografía en tres meses, la cual revela un crecimiento de dicha masa. Se le propone nuevamente una actitud quirúrgica y el paciente acepta.

Fue intervenido realizándose una orquiectomía izquierda vía inguino-escrotal, con ligadura alta del cordón espermático.

La pieza extirpada correspondió a una masa tumoral sólida, fasciculada, blanquecina, pétrea, que mide $75 \times 70 \mathrm{~mm}$ y que desplaza e infiltra testículo. No se observan anejos testiculares normales, estando todos ellos sustituidos por la masa tumoral descrita. El borde quirúrgico del cordón espermático está marcadamente agrandado, con aspecto similar al de la masa tumoral. Histológicamente se observa una proliferación tumoral atípica y polimorfa constituida por áreas fasciculares constituidas por células ahusadas con atípia nuclear y frecuentes mitosis. (Fig. 2). También destaca la presencia de áreas tumorales constituidas por células epitelioides y rabdoides con núcleos pleomórficos y atípicos, que en ocasiones forman espacios alveolares con sangre en el interior. Estas células se acompañan de una extensa población de células gigantes multinucleadas de tipo osteoclástico y de focos de un material eosinófilo amorfo de tipo osteoide (Fig. 3).

En el estudio inmunohistoquímico realizado se observó positividad difusa para Vimentina y focal para desmina y CD-68 (+). La AML, AME y S-100 fueron negativas.

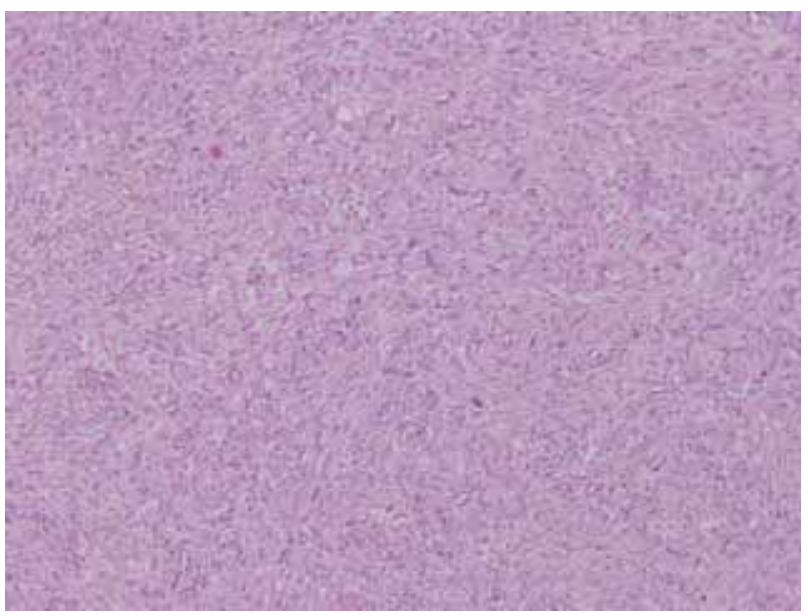

FIGURA 2. Áreas fasciculares constituidas por células ahusadas con marcada atipia celular y frecuentes mitosis (HE 10x).

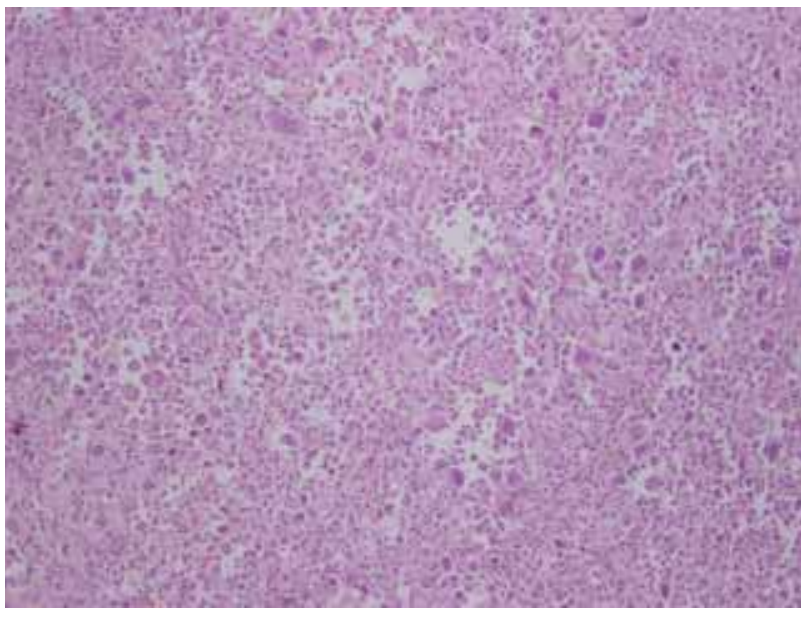

FIGURA 3. Extensa población de células gigantes multinucleadas de tipo osteoclástico. (HE 40x). 
El tumor afecta a todo el cordón espermático e invade el testículo, observándose únicamente un resto de testículo preservado en la parte inferior. Con todo lo expuesto, se llegó al diagnóstico de sarcoma pleomórfico compatible con Histiocitoma Fibroso Maligno de células gigantes originado en anejos testiculares.

En el TAC toraco-abdominal de control no se aprecian adenopatías retroperitoneales ni imágenes sugestivas de metástasis.

Se decidió no someter al paciente a tratamiento complementario, debido a su edad, patología asociada y la escasa aportación del mismo. A los seis meses de la cirugía el paciente se encuentra asintomático, sin signos de recidiva clínica ni radiológica.

\section{DISCUSIÓN}

El histiocitoma fibroso maligno (HFM) de cordón espermático representa una inusual localización, para el tumor más común de partes blandas encontrado en adultos. La primera referencia de este tipo de tumores se debe a O'Brien y Scout en 1961 cuando describieron el HFM como una entidad anatomopatológica diferente de los previamente categorizados como fibrosarcomas o variantes pleomórficas de otros sarcomas ${ }^{5,6}$. El HFM de cordón espermático generalmente aparece en varones con edades comprendidas entre los 50-70 años. Clínicamente se manifiestan como una masa poco dolorosa en región inguino-escrotal, de consistencia pétrea y de rápido crecimiento $^{7} \mathrm{El}$ diagnóstico preoperatorio de un tumor de cordón espermático es difícil. Esta lesión puede ser confundida con una hernia inguinal, un espermatocele, una orquioepididimitis o un tumor testicular. Aunque la ecografía puede ayudar a distinguir preoperatoriamente una masa testicular de una extratesticular en más de un 90\% de los casos, la variedad de estructuras que integran esta región puede hacer difícil el diagnóstico. El diagnóstico definitivo requiere el examen anatomopatológico del material resecado ${ }^{8,9}$. Los estudios de extensión incluyen la Rx. de Tórax, el TC abdominopélvico y la Resonancia Magnética de la región inguinoescrotal.

El HFM puede subdividirse histológicamente en cinco tipos, siendo la variante pleomórfica la más frecuente ${ }^{7}$. Macroscópicamente el tumor es fibroso, de color blanco nacarado, con una superficie al corte en espiral. Microscópicamente el HFM es un tumor anaplásico, con alto grado de pleomorfismo y células ahusadas y redondeadas ${ }^{9}$.
Para el grado y estadiaje de estas lesiones se utiliza como norma el propuesto por el American Joint Commite on Cancer (AJCC): considerando el tipo histológico, el grado tumoral (G1, G2), el tamaño (límite $5 \mathrm{~cm}$ ), la profundidad (superficial o profunda) $\mathrm{y}$, la presencia de metástasis ganglionares o a distancia. Se obtienen 4 estadios y 7 subestadios (A, B, C), siendo considerados el 1 y 2 como de bajo grado $\mathrm{y}$, el 3 y 4 de alto grado ${ }^{10,11}$.

Los factores pronósticos favorables de los sarcomas paratesticulares son: tumores de bajo grado, de pequeño tamaño, superficiales, resecados completamente, con márgenes quirúrgicos negativos y ausencia de metástasis.

Los diferentes subtipos histológicos tienen un riesgo de metástasis del 23 al 50\%. La variante pleomórfica, la más frecuente, tiende a metastatizar por vía hematógena, principalmente a los pulmones (90\%), las metástasis óseas y hepáticas son raras $(8$ y $1 \%$ respectivamente) y los ganglios linfáticos regionales sólo se ven afectados en un $12 \%$ de las ocasiones ${ }^{7}$.

Al momento del diagnóstico, no suele haber evidencia de metástasis a distancia en la mayoría de los casos de HFM de cordón espermático. Por lo que la orquiectomía radical por vía inguinal con ligadura alta del cordón espermático es el tratamiento recomendado.

El riesgo de recurrencia local del HFM en sus localizaciones habituales (extremidades, retroperitoneo) es del 44-66\%, cuando el tumor afecta al cordón espermático el riesgo disminuye al 18\%, aunque puede verse incrementado ante la presencia de nódulos satélites ${ }^{7}$. La radioterapia local y la quimioterapia sistémica pueden utilizarse como terapias adyuvantes, pero la efectividad de ambas terapias en el manejo de HFM de cordón espermático es controvertido ${ }^{8}$. Existen autores que consideran que la radioterapia después de la orquiectomía disminuye la tasa de recidiva local ${ }^{6,11}$. Como se comentó anteriormente, la diseminación tumoral se produce fundamentalmente por vía hematógena, por lo cual, la linfadenectomía retroperitoneal profiláctica tiene dudoso beneficio. Solamente está recomendada cuando hay adenopatías retroperitoneales claramente aumentadas de tamaño ${ }^{7}$.

En general el HFM, tiene un pronóstico ominoso, con unas tasas de supervivencia a los dos años del 53$63 \%$ y del $34-43 \%$ a los cinco años. En los tumores de 
cordón espermático, el pronóstico es más favorable, con tasas de supervivencia a los 2 y a los 5 años del 93 al 73\% respectivamente. Esto se debe a que en dicha localización el diagnóstico es más temprano, el tumor es más superficial y puede llevarse a cabo una intervención quirúrgica más efectiva ${ }^{8}$.

\section{REFERENCIAS}

1. Khoubeni B, Mishra V, Ali M, Motiwala H, Karin O. Adult paratesticular tumours. BJU Int. 2002;90(7):707-715.

2. Nistal M, Regadera J, Jareño E, Paniagua R. Inflammatory malignant fibrous histiocytoma of the spermatic cord. Urol Int. 1988;43(3):188-192.

3. Andreu García A, Schiefenbusch Munne E, Brotons Marquéz JL, Luque Moreno D, Llamazares Cachá G. Fibrohistiocitoma maligno de cordón espermático: aportación de un caso. Arch Esp Urol. 1994;47(5):525-528.

3. Andreu García A, Schiefenbusch Munne E, Brotons Marquéz JL, Luque Moreno D, Llamazares Cachá G. Malignant fibrohistiocytoma of the spermatic cord. Report of a case. Arch Esp Urol. 1994;47(5):525-528.

4. Urdiales-Viezma M, Fernández-Rodríguez A, Martos-Padilla S, Pichardo Pichardo S. Fibrohistiocitoma maligno de cordón espermático. Actas Urol Esp. 2002;26(8):581-584.

5. O`Brien JE, Stout AP. Malignant fibrous xanthomas. Cancer $1964 ; 17: 1445-8$.
6. Orio PF 3rd, Dahiya R, HermanT, Thomas CR Jr, Eng TY. Malignant fibrous histiocytoma of the spermatic cord: a case report. Am J Clin Oncol. 2002;25(3):227-229.

7. Ikinger U, Westrich M, Bersch W, Böttinger K. Malignant fibrous histiocytoma of the epididymis. Case report and review of the literature. Urol Int. 1999;62(2):106-109.

8. Uchida K, Oda T, Adachi H, Wakabayashi J, Hisasue S, Takagi Y. Malignant fibrous histiocytoma of the spermatic cord: a case report. Int J Urol. 1999;6(12):630-632.

9. Glazier DB, Vates TS, Cumming KB, Pickens RL. Malignant fibrous histiocytoma of the spermatic cord. J Urol. 1996;155 (3):955-957.

10. Müller Arteaga C, Egea Camacho J, Alvarez Gago T, Cortiñas González JR, Gonzalo Rodríguez V, Fernández del Busto E. Liposarcoma de cordón espermático. Asociación con carcinoma de próstata. Comunicación de un caso y revisión de la literatura. Actas Urol Esp. 2005;29(7):700-703.

11. Folpe A, Weis S. Paratesticular Soft Tissue Neoplasm. Semin Diagn Pathol. 2000;17(4):307-318.

Correspondencia autor: Dr. S. Martín Martín Servicio de Urología.

Hospital Clínico Universitario de Valladolid.

Ramón y Cajal, s/n. 47005 - Valladolid. Tel.: 983420000

E-mail autor: risimartin7@hotmail.com

Información artículo: Nota clínica

Trabajo recibido: febrero 2007

Trabajo aceptado: mayo 2007 